\title{
Caminos frustrados hacia la prefabricación arquitectónica. Estudio del sistema murario en las construcciones asociadas a la línea ferroviaria Teruel-Alcañiz
}

\section{Wrong ways to the architectural prefabrication. Study of the system wall in buildings associated with the railway line Teruel Alcañiz}

$\underline{\text { P. Verdejo }}^{(*)}$, G. López ${ }^{(* *)}$, G. Mocholí ${ }^{(*)}$

\section{RESUMEN}

La historia de la construcción no siempre ha estado repleta de éxitos en el desarrollo de nuevos sistemas constructivos, sin embargo, todos ellos han servido para desarrollar los avances que hoy en día conocemos. A finales del siglo XIX y principios de XX, la incipiente industria comenzará a dotar de nuevos materiales hacia la optimización constructiva. La arquitectura industrial hará uso de todos estos nuevos productos, formulándose como crisol de experimentación y desarrollo. El estudio de estos elementos prefabricados que materializaron las edificaciones hoy abandonadas de la línea ferroviaria Teruel-Alcañiz, permite, además de comprobar su estrategia para hacer frente a la ejecución de un elevado número de edificaciones en tempo y presupuesto limitados, afrontar bajo su conocimiento futuros trabajos de intervención.

Palabras clave: Prefabricación, arquitectura ferroviaria, muros de carga, piedra artificial, patrimonio industrial, encofrado perdido.

\section{ABSTRACT}

The development of new construction systems has not always been successful, however, every system has served to develop the advances that we know today. Regarding the development of prefabricated architecture, the emerging industry will begin to provide new materials towards constructive optimization. Industrial architecture will serve as a crucible of experimentation of all these systems. The objective of this paper focuses on the observation of a fragment of the constructive historical evolution in the use of prefabricated elements, through the special case of the buildings in the Teruel-Alcañiz railway, which resorted to prefabrication as a strategy to deal with the execution of a large number of buildings, under limited conditions of time and budget.

Keywords: Prefabrication, railway architecture, bearing walls, artificial stone, industrial heritage, lost formwork.

(*) Universidad CEU-Cardenal Herrera (Valencia, España).

(**) Universitat Politècnica de València (Valencia, España).

Persona de contacto/Corresponding author: pverdejo@uchceu.es (P. Verdejo)

ORCID: http://orcid.org/oooo-0001-6989-0871 (P. Verdejo), http://orcid.org/oooo-00o2-0136-5613 (G. López), http://orcid.org/oooo-0001-9782-8821 (G. Mocholí)

Cómo citar este artículo/Citation: P. Verdejo; G. López; G. Mocholí (2018). Caminos frustrados hacia la prefabricación arquitectónica. Estudio del sistema murario en las construcciones asociadas a la línea ferroviaria Teruel-Alcañiz. Informes de la Construcción, 70(550): e259. https://doi.org/10.3989/id.59141

Copyright: (c) 2018 CSIC. Este es un artículo de acceso abierto distribuido bajo los términos de la licencia de uso y distribución Creative Commons Reconocimiento 4.o Internacional (CC BY 4.0). 


\section{INTRODUCCIÓN}

En la actualidad, el uso de elementos prefabricados para agilizar los procesos constructivos se encuentra plenamente implantado en el ámbito arquitectónico, apareciendo, día tras día, nuevas propuestas que van desde la prefabricación de algunos de sus elementos, como la estructura o cerramientos, hasta el modelo completo arquitectónico. Sin embargo, la optimización constructiva alcanzada actualmente no ha sido inmediata, sino fruto de un proceso de experimentación continua.

Tras la Revolución Industrial, la incipiente industria comenzará a desarrollar y suministrar al mercado toda una gama de nuevos materiales y elementos, en una búsqueda continua de reducción de costes y adecuación de recursos, capaz de agilizar los procesos constructivos como marca de identidad que desencadenaría una "revolución constructiva" frente a los procesos tradicionales.

Será principalmente en este ámbito arquitectónico donde la influencia de nuevos planteamientos científicos y técnicos permitirá una nueva organización productiva, generando la aparición de conceptos como la estandarización, repetición y compatibilidad, que serán asumidos en la industria como principios de economía de mercado. Estos rasgos se materializarán tanto en sus productos como en sus nuevas manifestaciones arquitectónicas, donde llegarán a plasmarse unas formas, técnicas y procesos, como parte integrante de la producción industrial (1).

Inicialmente, las edificaciones industriales emplearán los materiales y técnicas tradicionales más comunes de cada zona como la piedra, el ladrillo o la teja cerámica, en una correcta adaptación a su lenguaje. Pero, ante la aparición de nuevos materiales y sus ventajas, relegarán los tradicionales a un segundo plano, estableciéndose una convivencia gradual e ineludible entre los materiales y técnicas más comunes con las más novedosas, que con el paso de los años ganarán protagonismo en el proceso constructivo.

Criterios como funcionalidad, racionalidad y economía, se encontrarán implícitos en su construcción, relacionados íntimamente con los nuevos materiales proporcionados desde la industria, que se mostrarán de manera sincera y coherente con sus singulares características y propiedades.

El cemento artificial procurará, a partir de las últimas décadas del siglo XIX, la aparición de un extenso repertorio de nuevos productos para la construcción. La evolución de este material, a la par del progreso y capacidad industrial, propició que empresas estadounidenses, francesas o alemanas, principalmente, desarrollaran una amplia gama de elementos prefabricados, encaminados a agilizar y abrir nuevos caminos en el proceso constructivo (2). Bloques de hormigón para la ejecución de muros, adoquines para viales o bloques de piedra artificial para los espigones de los puertos, recogen parte de esta enorme diversidad de productos propuestos desde la industria, y que se regirán por los nuevos planteamientos surgidos desde el pensamiento científico, el mercado y la producción.

La presente investigación recoge el sistema constructivo de las 33 edificaciones ferroviarias de la línea entre Teruele-Alcañiz, haciendo hincapié en las piezas industriales prefabri- cadas, sobre todo de hormigón, su interesante disposición y su efímero uso.

\subsection{Antecedentes}

La arquitectura ferroviaria será una de las tipologías edificatorias aparecidas a raíz de las crecientes necesidades de la sociedad industrial, justificada ante la aparición de nuevos medios de transporte que posibilitarán el desplazamiento de mercancías y personas. Las compañías ferroviarias representaron, durante la segunda mitad del siglo XIX y principios del $\mathrm{XX}$, una de las grandes potencias económicas del país, constituyendo una de las mayores inversiones en infraestructuras llevadas a cabo en España.

El inicio y expansión de la red ferroviaria en España se realizará casi dos décadas después que en el resto de países europeos. El anhelo de progreso junto a la precariedad de la economía del país, abocará a que el Estado delegue el desarrollo ferroviario a concesiones privadas formadas por capital extranjero que, ante la falta de personal cualificado, aportarán sus propios ingenieros, lo que implicará, paralelamente, la introducción de nuevos procedimientos, técnicas y materiales. Además, para permitir el normal funcionamiento del ferrocarril se tuvo que hacer frente a la construcción de una inmensa cantidad de infraestructuras y edificaciones en apenas cuatro décadas (3), lo que supone un espacio de tiempo relativamente breve, y la justificación en el uso de nuevos procedimientos y técnicas, que serán introducidas tras ser experimentadas previamente durante más de dos décadas por los ingenieros de países europeos, como franceses, ingleses o belgas (4).

El procedimiento para la puesta en marcha de una nueva línea ferroviaria consistía, en primera instancia, en poner en funcionamiento el propio ferrocarril, analizar los datos de rentabilidad, y proceder, en caso positivo, a la construcción de todas las edificaciones al servicio de la actividad. En términos técnicos, la práctica habitual entre las compañías privadas ferroviarias conllevaba explanaciones, túneles, viaductos o infraestructuras propias para facilitar la puesta en marcha de la línea, para continuar, según viabilidad económica, con la construcción de los edificios de viajeros, muelles de mercancías o depósitos de máquinas y finalizar con las edificaciones auxiliares (5).

Por tanto, debe entenderse que para estas empresas, a excepción de las estaciones de cabecera de una línea ferroviaria, que en cierta manera podían representar la imagen pública y comercial de la compañía, el resto de edificaciones dispuestas a lo largo de un trazado ferroviario no suponían más que un gasto económico, no encontrándose entre sus prioridades e incluso llegando a ser prescindible a la hora de afrontar la puesta en funcionamiento de una nueva explotación ferroviaria.

Es obvio, pues, que las compañías promotoras del ferrocarril aplicaran todas las posibles estrategias que les permitieran reducir, en la mayor medida posible, el coste y los recursos necesarios para hacer frente a estas edificaciones. Como consecuencia, funcionalidad y optimización se convertirán en los rasgos definitorios de esta nueva tipología, que se basará en una planificación minuciosa y previa del espacio, definida por las necesidades, sus exigencias funcionales y la pura economía (6). 
Estrategias como la seriación y repetición de sus edificaciones, la estandarización de diferentes modelos de construcciones según las necesidades, la simplicidad y sinceridad constructiva o la utilización de los nuevos materiales proporcionados desde la industria, serán asumidas por los nuevos ingenieros encargados de planificar y construir la incipiente actividad ferroviaria, convirtiéndose en cualidades propias de sus edificaciones.

\subsection{Reseña histórica}

Con la llegada del gobierno del General Primo de Rivera en la segunda década del siglo XX, el Estado llevará a cabo una fuerte inversión en infraestructuras, de las cuales el ferrocarril será una de las grandes beneficiarias (7). Entre los nuevos proyectos se pretenderá materializar uno de los más vastos trazados de la red ferroviaria española, la línea Saint Girons-Baeza, surgida a finales del siglo XIX según intereses mayoritariamente franceses, que pretendían unir sus colonias del norte de África con París. En un principio el estado español se mostró receloso a abrir nuevos accesos en la frontera natural de los Pirineos pero, finalmente, accedió, al entender sus ventajas como precursor hacia la industrialización del país y para favorecer la exportación de los productos nacionales al resto de Europa (8). La ejecución de los trabajos se iniciará a diferente ritmo a lo largo de todo su trazado, tanto de las infraestructuras (puentes, viaductos, terraplenados o túneles) como de las edificaciones, cosa inusual en los procedimientos de las concesiones privadas, pero justificado ante el interés del Estado (9) (Figura 1).

Dada la envergadura de la línea, de más de 800 kilómetros, se procedió a subdividir administrativamente en seis tramos (Figura 2) y tras décadas de trabajos, nunca llegaría a ponerse en funcionamiento debido a una triple paradoja que vino a malograr todo el esfuerzo realizado: por una parte se vio interrumpido por la fractura de la Guerra Civil española, que desbastó todo el país y lo dejo en un estado económico límite; por otra parte, el proyecto se inició tardíamente, cuando el transporte ferroviario decaía en favor del modelo americano, que potenciaba el automóvil y el transporte por carretera; finalmente, se cuestionó su rentabilidad siendo, sin embargo, uno de sus objetivos principales el postularse como un eje vertebrador para la industrialización y regeneración de las zonas más deprimidas de la Península.

Después de varios intentos por parte del gobierno franquista para retomar los trabajos, su construcción se abandonaría definitivamente a principios de la década de los sesenta, tras las recomendaciones recogidas en el informe (10) sobre el desarrollo económico de España del Banco Mundial'

Actualmente algunas de estas edificaciones e infraestructuras han sido objeto de actuaciones para su reutilización, pero la inmensa mayoría permanece en el mismo estado que cuando fueron paralizados los trabajos como testimonio de este infructuoso proyecto.

\subsection{La sección Teruel-Alcañiz}

La sección que discurre entre las poblaciones aragonesas de Teruel y Alcañiz presenta una longitud aproximada de $165 \mathrm{~km}$ a través de una orografía abrupta. El proyecto fue redactado por el ingeniero turolense Bartolomé Estevan Mata, iniciándose los trabajos de construcción en 1927 (11).

Las edificaciones conservadas difieren en el número original de las proyectadas (12), habiéndose inventariado en la actualidad un total de nueve edificios de viajeros, ocho muelles de mercancías, un depósito de máquinas, seis lampisterías/retretes y nueve viviendas ferroviarias (13).

Se caracterizan en primer término por presentar un mismo estilo formal con valores propios del regionalismo característico de principios del siglo XX, adaptados al lenguaje industrial, que, a pesar de la dispersión y remota localización, potencian una lectura uniforme del conjunto² (Figura 3).

Los materiales utilizados en la ejecución, hormigón, fibrocemento y prefabricados cumplen un doble objetivo: por un lado, la viabilidad económica en una época de dificultades económicas, que permite además un lenguaje apropiado para las nuevas políticas de promoción gubernamental y, en segundo lugar, dotar de una técnica ágil y flexible a unos edificios con diversidad de tamaños, requisitos y emplazamiento.

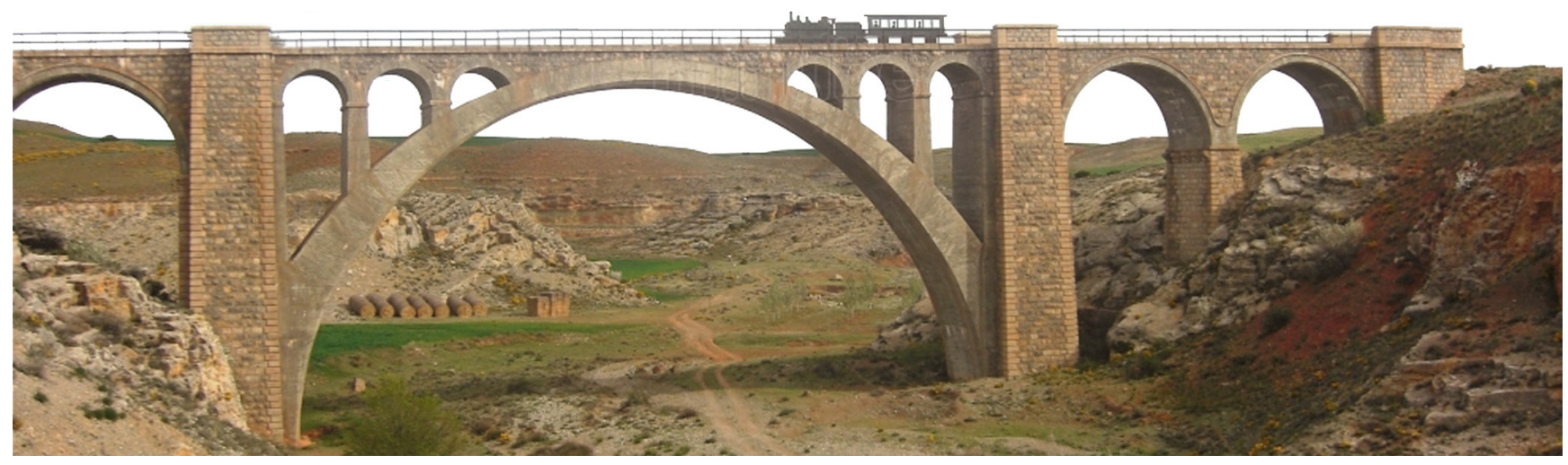

Figura 1. Vista del del viaducto sobre el barranco de los Canales (Alfambra, Teruel).

\footnotetext{
${ }^{1}$ El informe del Banco Mundial de agosto de 1962 sobre el desarrollo económico de España recomendaba abandonar las inversiones en nuevas líneas y centrar el esfuerzo presupuestario en mejorar la red existente.

${ }^{2}$ Como puede apreciarse en la figura 3, los edificios de viajeros, lampisterías y muelles además de las casillas ferroviarias, guardan una estrecha relación formal, estética y constructiva. Todos ellos se encuentran resueltos con el mismo sistema murario de escueta ornamentación en ladrillo cerámico, y cubiertas inclinadas de teja cerámica, difiriendo principalmente en las dimensiones de cada tipología de edificio.
} 


\subsection{Material y métodos}

El primer obstáculo para estudiar estas edificaciones ha sido la información existente sobre la misma. Las escasas fuentes documentales que hacen referencia a su construcción, se limitan a los expedientes relativos al litigio entre la constructora y la Administración.

Fue por tanto imprescindible realizar un primer trabajo de campo mediante un levantamiento gráfico exhaustivo, que permitió definir su geometría, materiales y composición constructiva, inventariando todas y cada una de las construcciones existentes hoy en día.

La existencia de alguna edificación derruida ha favorecido la lectura interna de sus muros, definiendo la geometría, espe- sores de las capas, materiales y detallando con precisión los puntos singulares del hecho físico construido.

Dada la singularidad y desconocimiento del sistema constructivo encontrado, se procedió a profundizar en us conocimiento mediante la extracción y ensayo de varios testigos. $^{3}$

\subsection{La construcción. Entre la dualidad tradición- innovación}

La introducción de los nuevos materiales en la construcción arquitectónica ha sido históricamente un proceso progresivo, donde se procedía a su ejecución de manera tradicional, o bien conviviendo con técnicas tradicionales hasta resolver los problemas técnicos generados (14).

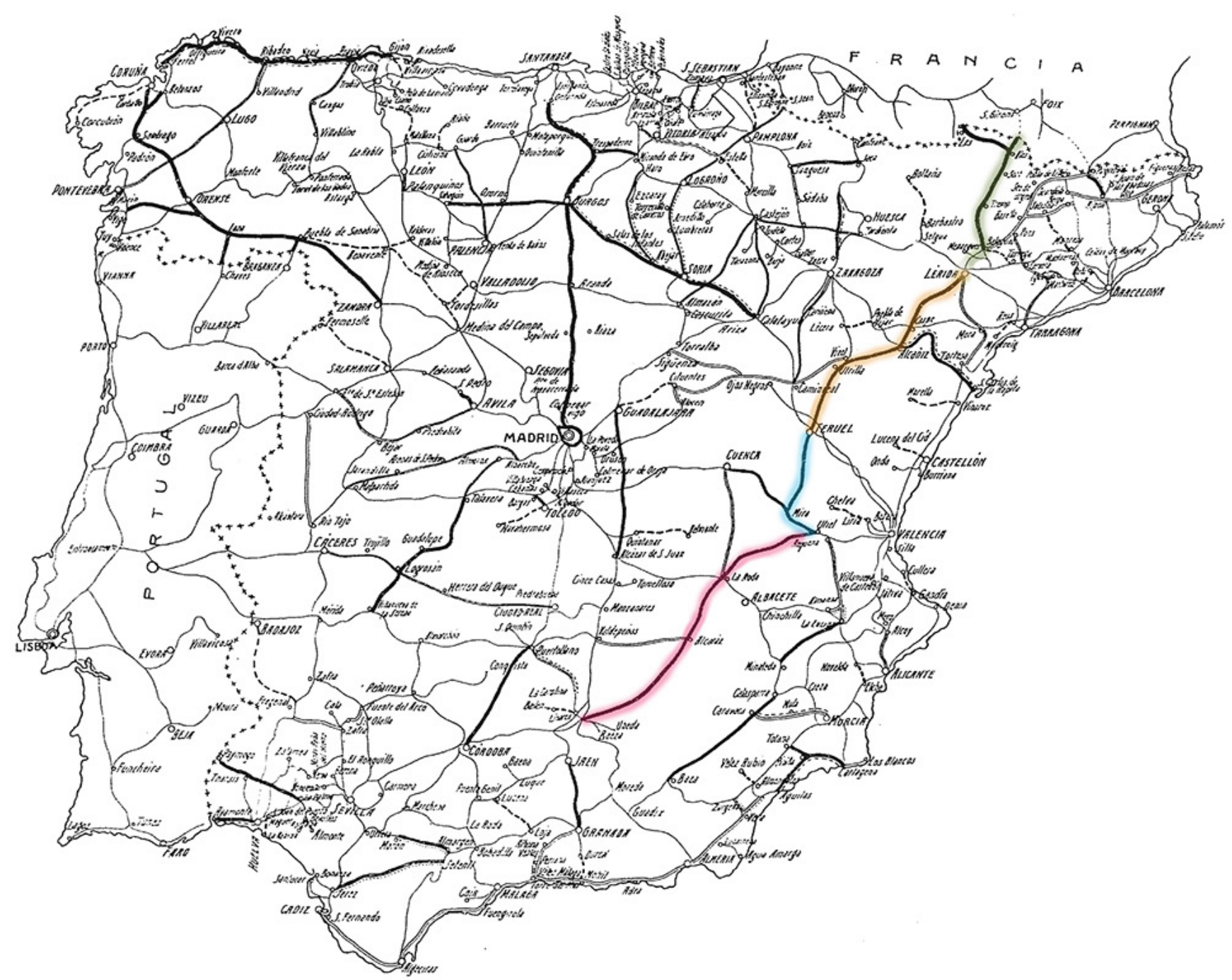

Figura 2. Plano de las líneas del Plan General de Ferrocarriles, remarcando el Saint Girons-Baeza. Fuente: Anteproyecto del Plan General de Ferrocarriles. Revista Obras Públicas (1925). tomo I, 2426 o6, P144.

\footnotetext{
3 Se tomaron un total de 10 testigos del edificio de viajeros de Peralejos, la casilla ferroviaria de Perales de Alfambra y el acopio de piezas de piedra artificial ubicado en la población de Fuentes Calientes. Una vez extraídos los testigos se prepararon las muestras mediante el corte y pulido de sus caras, resultando piezas de geometría cilíndrica de $150 \mathrm{~mm}$ de altura por $74 \mathrm{~mm}$ de diámetro para la piedra artificial, y de $44 \mathrm{~mm}$ de altura por 74mm de diámetro para el hormigón de relleno y las piezas prefabricadas, por lo que al no ajustarse a una relación 2:1 como establece UNE-EN 13791, se procedió a aplicar a estas últimas muestras un coeficiente de corrección de o,8o para corregir la influencia de la esbeltez de las probetas en el ensayo.
} 


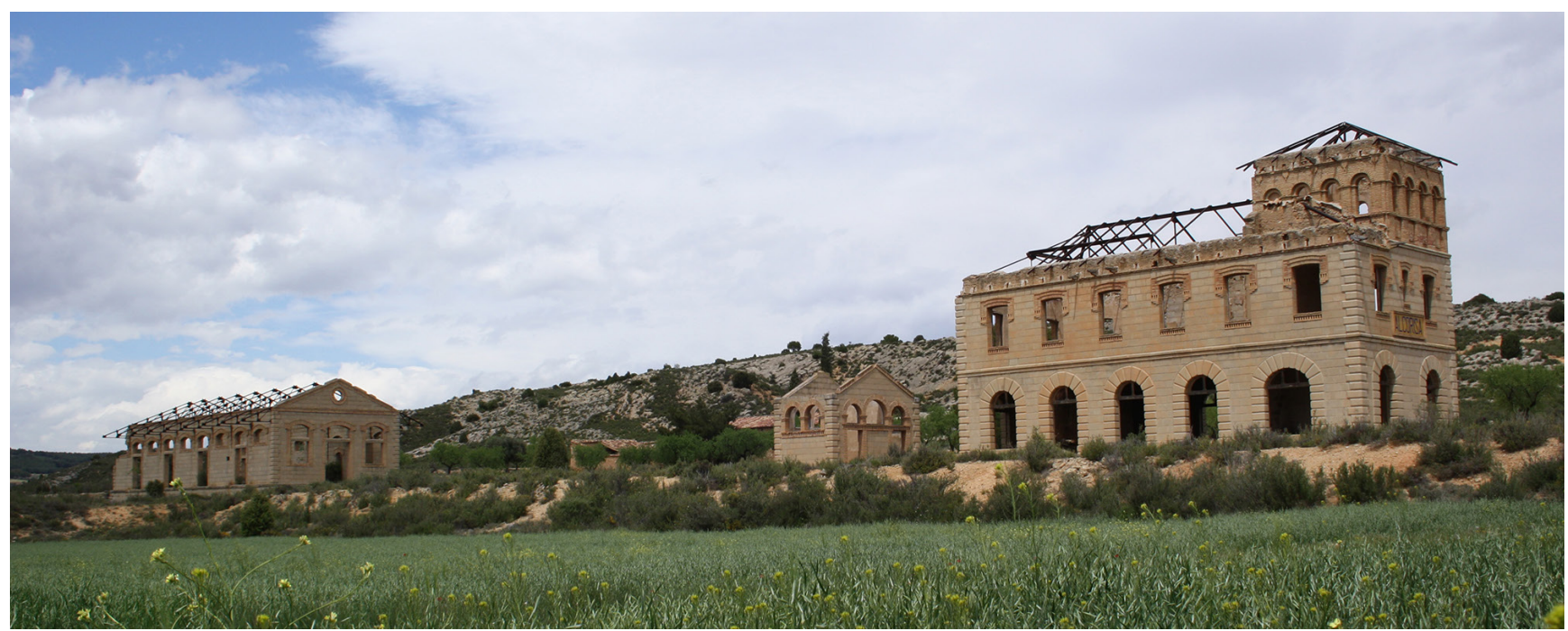

Figura 3. Complejo de la estación ferroviaria de Alcorisa (Teruel).

Las edificaciones de la línea ferroviaria Teruel-Alcañiz se formulan como una instantánea que representa este momento en la historia de la evolución constructiva.Su vocación de tipología arquitectónica al servicio del ferrocarril las hace situarse estrechamente vinculadas con la industria, dejándose influenciar por todos sus principios, premisas y características. Pero, a su vez, como parte de un proyecto de Estado, tienen la necesidad de transmitir una imagen de edificio público reconocible y cercano a los gustos populares.

Esta dualidad se observará en la resolución por ejemplo de sus cubiertas, mediante cerchas metálicas tipo Howe, formada por perfilería roblonada en hierro laminado L70 en disposición simple en tornapuntas y tirantillos, o doble en pares y tirantes. Sobre estas se dispondrán correas con UPN 200, que sustentarán cabios metálicos IPN 80. Tras el entramado metálico, se utilizarán rastreles de madera para formalizar un plano que sirve como soporte continuo para alojar la cubrición de teja cerámica, obteniendo una imagen externa de cubierta tradicional.

De igual forma se puede apreciar el uso de materiales tradicionales, como el uso de ladrillos cerámicos macizos, en todos los alfeizares, dinteles e impostas mediante una disposición a sardinel, frente a la resolución de los forjados, ejecutados mediante el empleo de perfiles metálicos laminados IPN 200 dispuestos a intereje de $76 \mathrm{~cm}$, presentando una luz máxima de 6,53 metros y resolviendo el elemento intermedio mediante la formación de revoltón de una única hoja de ladrillo macizo, rellenándose con material de aporte hasta formar el plano horizontal. (Figura 4).

Más allá de la justificación de uso de estos materiales por un condicionante formal, existen otros aspectos por los que se han seguido utilizando en estas construcciones. En el caso de las cimentaciones prima el uso de mampuestos y mortero de cal a la manera tradicional, frente al hormigón que, a priori, podría presentar una mayor reducción en cuanto coste y tiempo de ejecución, debido al gran volumen de piedra extraída de la excavación de túneles, trincheras o de las propias edificaciones.

Teniendo en cuenta que la anchura de la cimentación varía entre 95 y $105 \mathrm{~cm}$. y que los espesores medios de los muros que soportan es de unos $65 \mathrm{~cm}$, se establece una relación en cuanto a la anchura de la cimentación de 1,5 veces el espesor. Esta proporción era utilizada de forma habitual en las edificaciones de la época, por lo que demuestra que la cimentación se encontraría ejecutada al modo tradicional en cuanto a materiales, técnica y diseño (15).

Por otro lado, cuando las condiciones del terreno no resultaban favorables y era necesario buscar un firme de apoyo más profundo, se observa el uso de técnicas tradicionales con utilización de materiales modernos como el hormigón armado. Es el caso del edificio de viajeros de Peralejos (Teruel), donde para realizar la descarga de los muros se ha empleado un sistema de combinación entre zapatas o pozos con arcos de apoyo. El empleo del ladrillo en la ejecución de los arcos de descarga, en combinación con el hormigón armado para el atado de la cimentación mediante riostras, permite demostrar la convivencia entre sistemas constructivos conocidos y experimentados con materiales más modernos e idóneos para la función propuesta (Figura 5).

Otros elementos constructivos, bien por su extensión o por su naturaleza, como es el caso de los cerramientos, hacen oportuno y ventajoso el empleo de materiales y técnicas con un carácter más industrial, ligadas a conceptos propios de la flexibilidad, economía y optimización de recursos y tiempos.

\section{SISTEMA MURARIO}

\subsection{El sistema y su construcción}

El elemento que sintetiza las funciones de elemento portante y cerramiento llegando a identificar y caracterizar los edificios dispuestos en la sección estudiada, es la fábrica que configura sus fachadas, entendida como la parte más compleja de la obra.

La estrecha interacción entre los rasgos y estrategias propias de la arquitectura industrial con la arquitectura propia del entorno queda reflejada en la imagen de los cerramientos que conforman estas edificaciones. La composición de sus fachadas, de influencia regionalista, es una combinación de elementos renacentistas y mudéjares, característicos de la arquitectura aragonesa, con una sobria ornamentación de ladrillo cerámico 

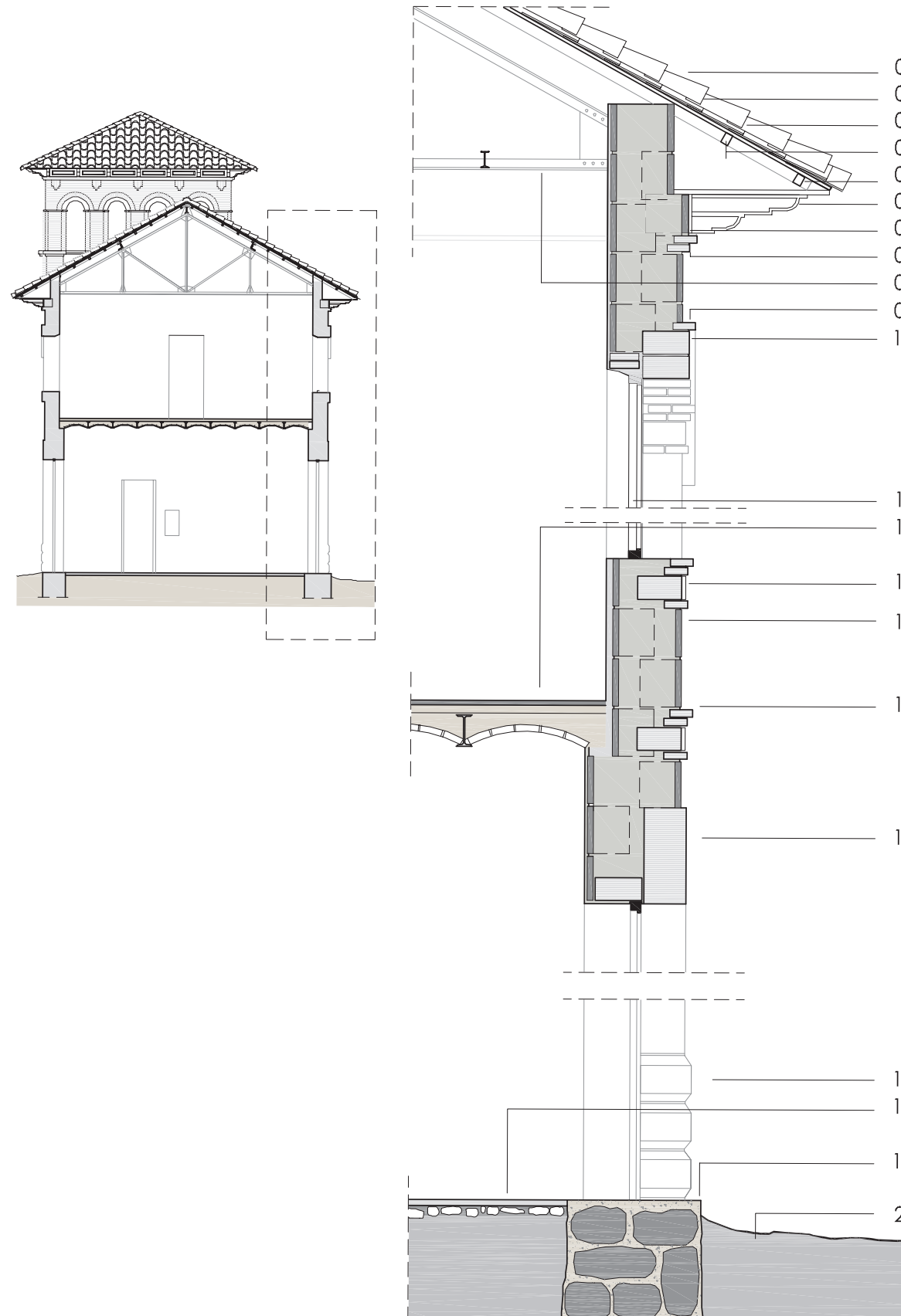

11_Carpinteria de madera

12_ Forjado formado por perfiles IPN 200 y revoltones de piezas cerámicas. 13_Alfeizar de ladrillo cerámico.

14_Muro formado por piezas de bloque hormigón $(49 \times 30 \times 24)$ rellenadas con hormigón.

15_Imposta de ladrillo cerámico aparejado a dentelladas de sardinel a canto

16_Dobela realizada con piedra artificial

17_ Piezas de piedra artificial.

18_ Solado de hormigón y mampuestos, acabado con cemento ruleteado.

19_ Cimentación con mampuestos de piedra caliza y mortero de cal 20_ Terreno

Figura 4. Sección constructiva de los edificios de viajeros.

en sus impostas, cornisa o dinteles, depurados bajo el carácter industrial de estas construcciones (Figura 6).

El sistema murario, común a todas las edificaciones exceptuando el cuerpo de la torre, presenta dos elementos claramente definidos en función de los distintos materiales empleados: el zócalo de piedra artificial y las piezas prefabricadas de hormigón.

Todas las edificaciones de la línea ferroviaria se asientan sobre un zócalo, que alcanza una altura aproximada de un metro desde el suelo, configurando los antepechos y alfeizares de las ventanas. Este podio está ejecutado con piedra artificial, a modo de sillería almohadillada en chaflán.

Las piezas utilizadas muestran dimensiones de 90x30x55 $\mathrm{cm}$., realizadas en forma de ortoedro o paralelepípedo rec- tangular, cuyas caras forman entre sí ángulos diedros rectos, y en la cara exterior presenta un rehundido perimetral achaflanado, dotándole de una disposición exterior a modo de almohadillado. Se encuentran fabricadas a partir de mortero de cemento y cal con diversas granulometrías de áridos, llegando a presentar incluso pequeños ripios (Figura 7).

Este basamento, además de configurar la base de la estructura muraria resistente y másica antes de ser transmitida a la cimentación, refuerza la imagen del conjunto de edificaciones. Desde el punto de vista compositivo, se utiliza este recurso como estrategia estética para enfatizar la imagen de la estación hasta llevarla a la categoría de edificio público, resaltada por el uso de una potente textura de reminiscencias renacentistas. Todas las fachadas se encuentran rematadas en sus esquinas con piezas a modo de paralelepípedos rectangulares con dos de sus caras laterales almohadilladas, 


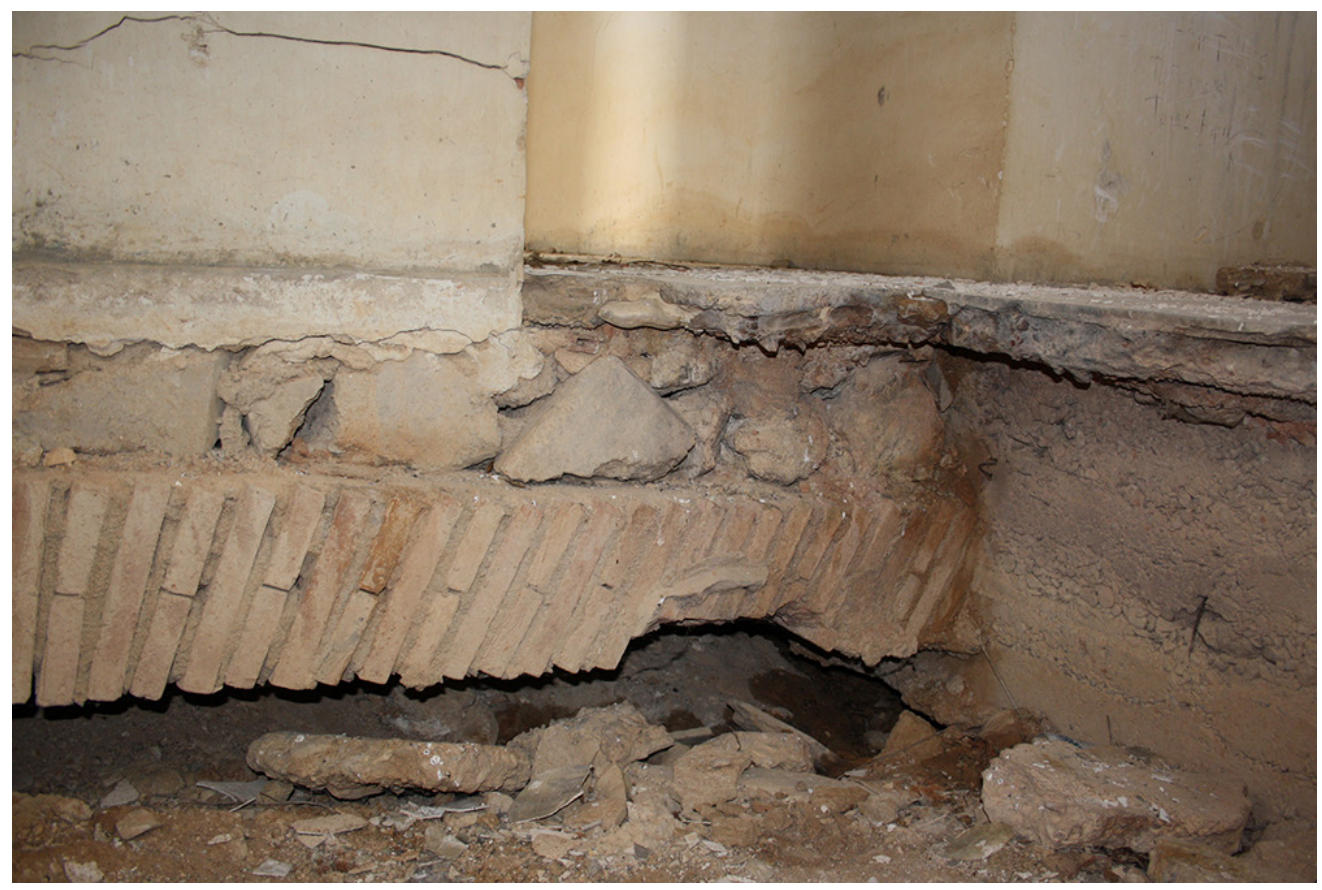

Figura 5. Vista del sistema de cimentación mediante arcos de descarga de ladrillo arriostrados con vigas de hormigón.

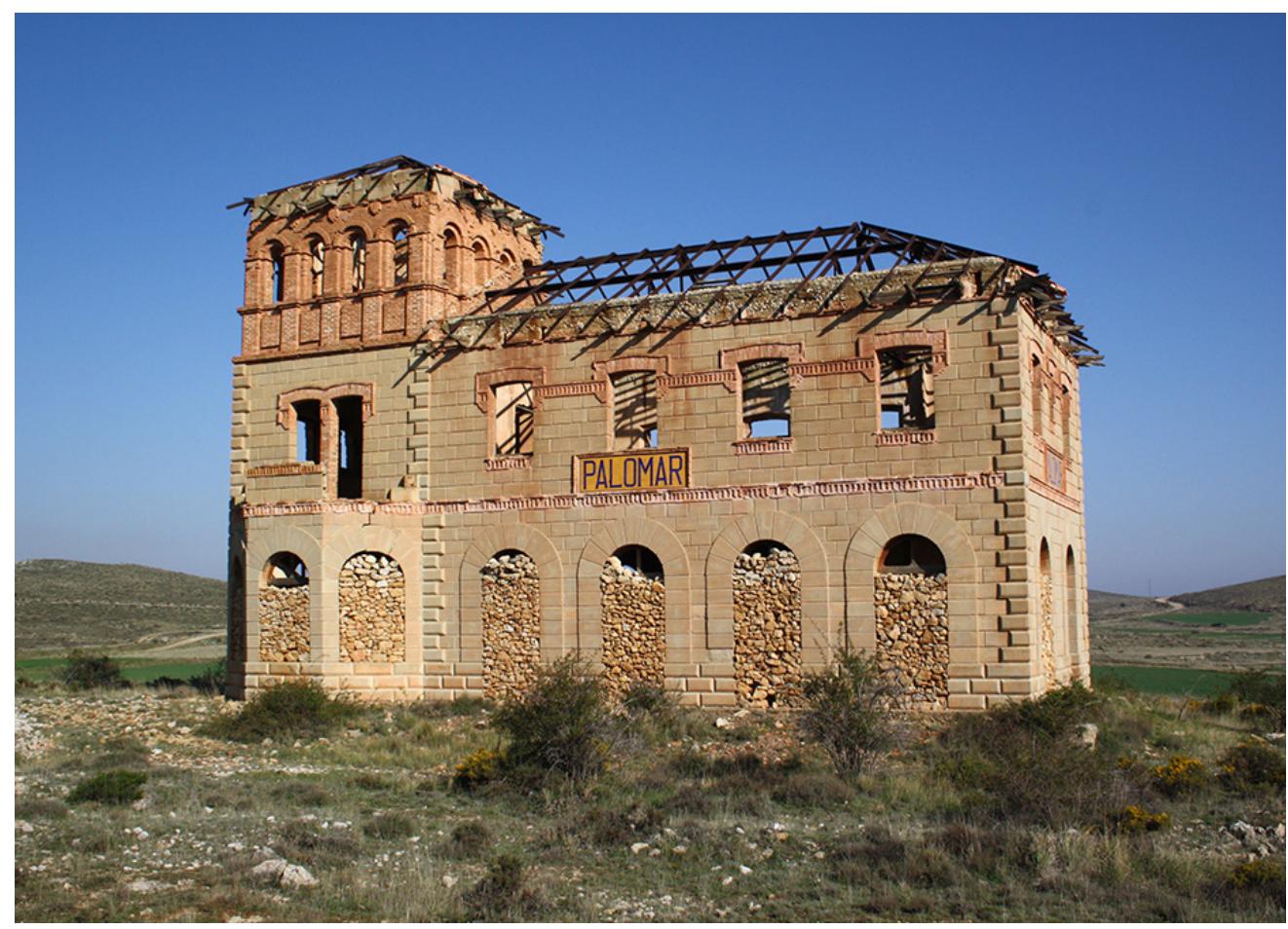

Figura 6. Vista del edificio de viajeros de la estación de Palomar de Arroyos.

presentando uno de sus laterales menor longitud. Su disposición, de manera alternada, permite crear de forma audaz, con una única pieza prefabricada, un juego dimensional a cada lado de la esquina de las fachadas. Su intención no será únicamente como recurso plástico para subrayar la visión de las esquinas, sino que permitirá resolver constructivamente la intersección entre los paños de fachadas.

Al contrario de lo que venía siendo habitual, el empleo de la piedra artificial adquirirá un valor más allá de lo ornamental y decorativo, alcanzando propiedades mecánicas que la harán participe de la resolución estructural de estas edificaciones, comprobando con el paso de los años su buen comportamiento $(16)$.

Aunque este material ya era utilizado desde finales del siglo XIX por su dureza, buen aspecto y economía (17), su destino era principalmente en elementos ornamentales o piezas para adoquines o espigones, siendo inusual el uso en edificación, al menos de una forma tan extensiva y adquiriendo una función estructural, por lo que su empleo en estas construcciones puede considerarse como único y singular. 


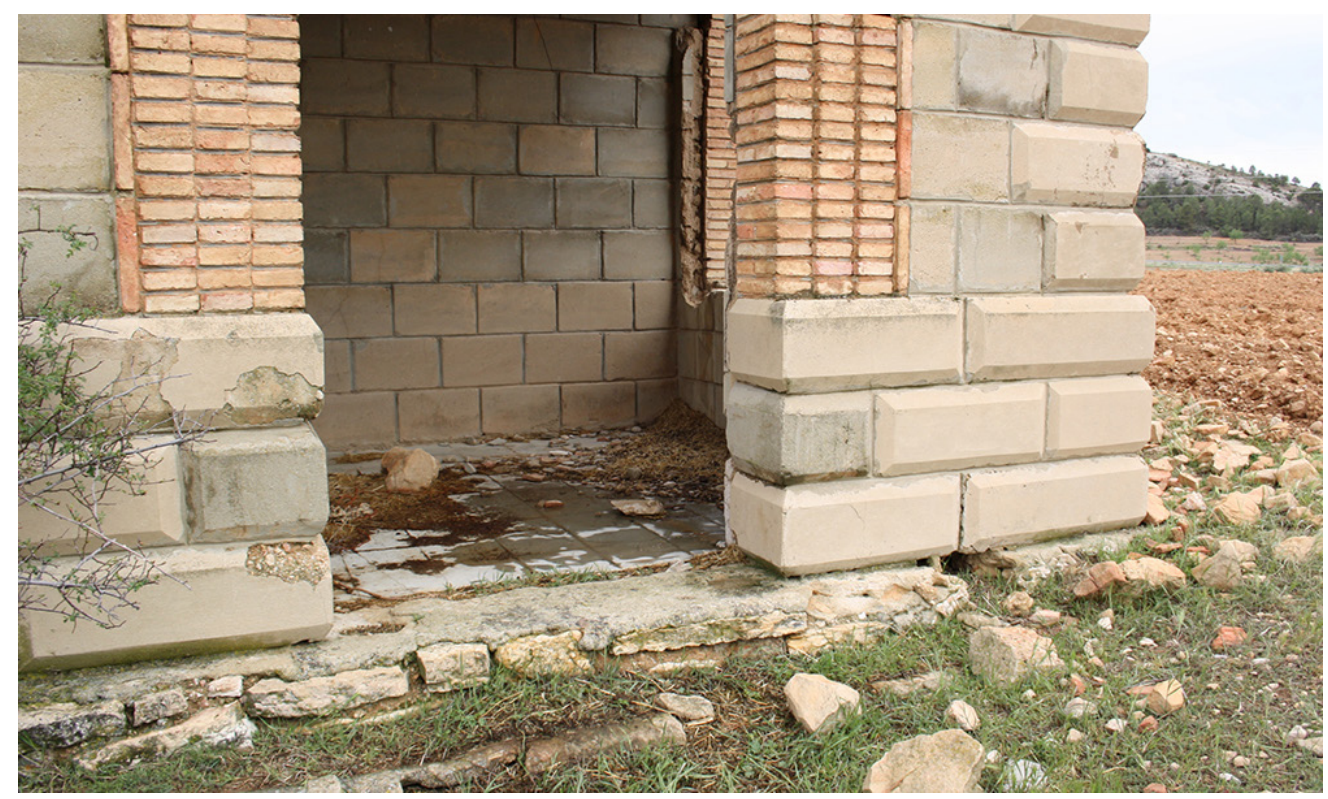

Figura 7. Utilización de piezas de piedra artificial en el zócalo del edificio.

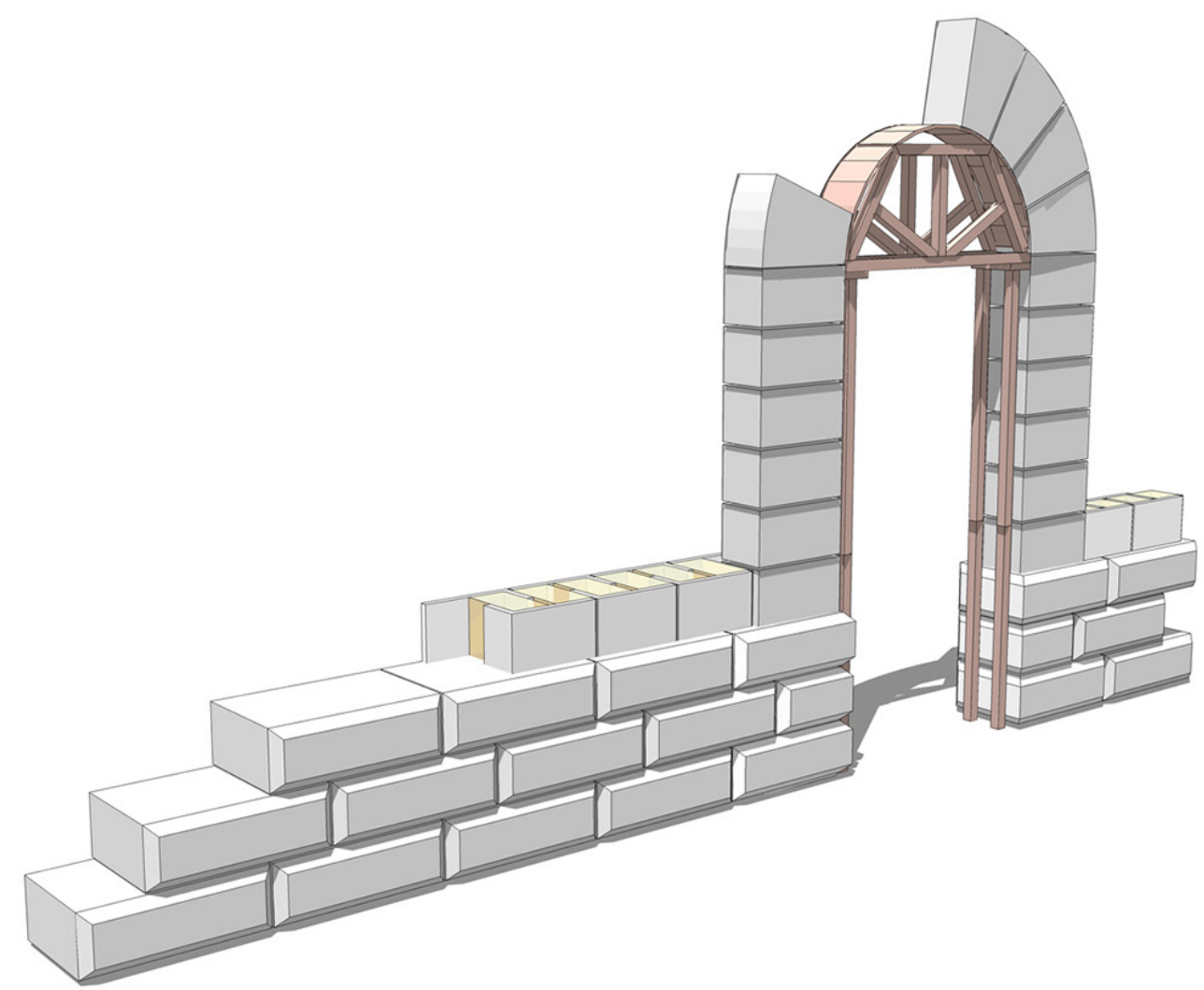

Figura 8. Infografía del montaje de las piedras artificiales en zócalo y arcos de los edificios de viajeros.

También aparece el uso de la piedra artificial en la resolución de las arcadas de medio punto que configuran los vanos inferiores de las fachadas de los edificios de viajeros. Estas piezas presentan unas dimensiones de 45x60x20 con una geometría análoga a las dovelas de piedra tanto en materialidad, geometría y forma de trabajo mediante una disposición radial, solucionando con un único modelo de pieza, la generación de todos los arcos (Figura 8).

La justificación en el empleo de este material se basa en la imposibilidad de recurrir tanto a grandes alardes estéticos como al uso y labra de la piedra, difícilmente asumible para la ejecución de estaciones intermedias ferroviarias, utilizando por tanto la piedra artificial, como sustitutivo económico a la piedra natural.

Destaca el cuidado con el que se resuelven distintos encuentros, como el ejemplo de la esquina, con piezas de piedra artificial, y la imposta de ladrillo cerámico dentellado que recorre horizontalmente las fachadas. En este caso las piezas prefabricadas disponen de un rebaje a modo de retranqueo en uno de sus lados cortos, para permitir alojar los ladrillos 
sin necesidad de realizar trabajos de corte en la piedra y los ladrillos.

Sin menoscabo de la importancia de la piedra artificial, el material que llega a definir de forma completa los paños de fachadas, tanto por su singularidad constructiva como por la extensión en su uso, es la pieza prefabricada de hormigón.

Las piezas prefabricadas presentan una forma en "L" de dimensiones 49x30x24 cm. y un espesor de $4 \mathrm{~cm}$. Su disposición se realiza de forma alternada y enfrentando su lado corto al intradós del muro, lo que les presta una mayor estabilidad a la hora del montaje de las piezas debido a su poco espesor, así como un mayor trabado del muro una vez rellenado su intradós (Figura 9).

El interior que queda confinado por estas piezas, a modo de encofrado perdido, se rellena mediante un vertido de hormigón a base de cemento, arena, grava e incluso de ripios, obteniendo un muro de hormigón en masa continuo, aunque con una terminación manufacturada por el exterior uniforme y de calidad.

Las piezas se encuentran dispuestas a partir del zócalo de piedra artificial, distanciándolas así del contacto con el terreno, transmitiendo una imagen a modo de fábrica de sillería.

Al igual que las piezas de piedra artificial, esta imagen de muro de sillería con acusado de juntas no es más que una marcada intención por obtener un aspecto de edificio público y notorio, cuando realmente se encuentra resuelto con un producto manufacturado.

Aunque la técnica constructiva empleada vuelve a tomar un sistema clásico como el opus emplectum, la introducción de materiales más modernos hace reinterpretar esta práctica, sustituyendo tanto el relleno del intradós como la utilización de sillares de piedra natural por piezas de hormigón prefabricadas (18).

Una de las cualidades de esta técnica es que dependiendo de la separación de las piezas externas, la sección del muro puede adaptarse según las solicitaciones requeridas. Por tanto, un único sistema posibilita dar respuesta a todo el catálogo de edificaciones de la línea ferroviaria, obteniéndose espesores desde los $45 \mathrm{~cm}$ de las construcciones de una única altura, a los $65 \mathrm{~cm}$ en las que presentan dos alturas.

La estrategia del uso de este tipo de piezas se fundamenta en la resolución completa del elemento constructivo con un único modelo de pieza. De esta forma se optimiza el proceso constructivo, reduciendo tiempos de ejecución y costes productivos.

Sin embargo, todas estas ventajas parecen contradecirse con el uso exclusivo de este material en las construcciones estudiadas, no habiéndose encontrado otros ejemplos de edificaciones donde se haya utilizado, lo que mantiene inexplicable las causas de la interrupción de uso ante las iniciales bondades del sistema.

El análisis de estas construcciones también evidencia que la utilización de piezas prefabricadas no estaba completamente desarrollado o implementado como sistema constructivo completo. Es significante que las zonas de máxima tensión de las fachadas, como dinteles o esquinas, no han sido resueltas con piezas prefabricadas de hormigón, recurriendo al uso del ladrillo o de la piedra artificial (Figura 10). El motivo puede estar justificado por la necesidad de recurrir a otros materiales para enfatizar el reconocimiento de su arquitectura pero, dada la inexistencia en alguna edificación de las estudiadas, podría reconocerse también una falta de adecuación y desarrollo del sistema.

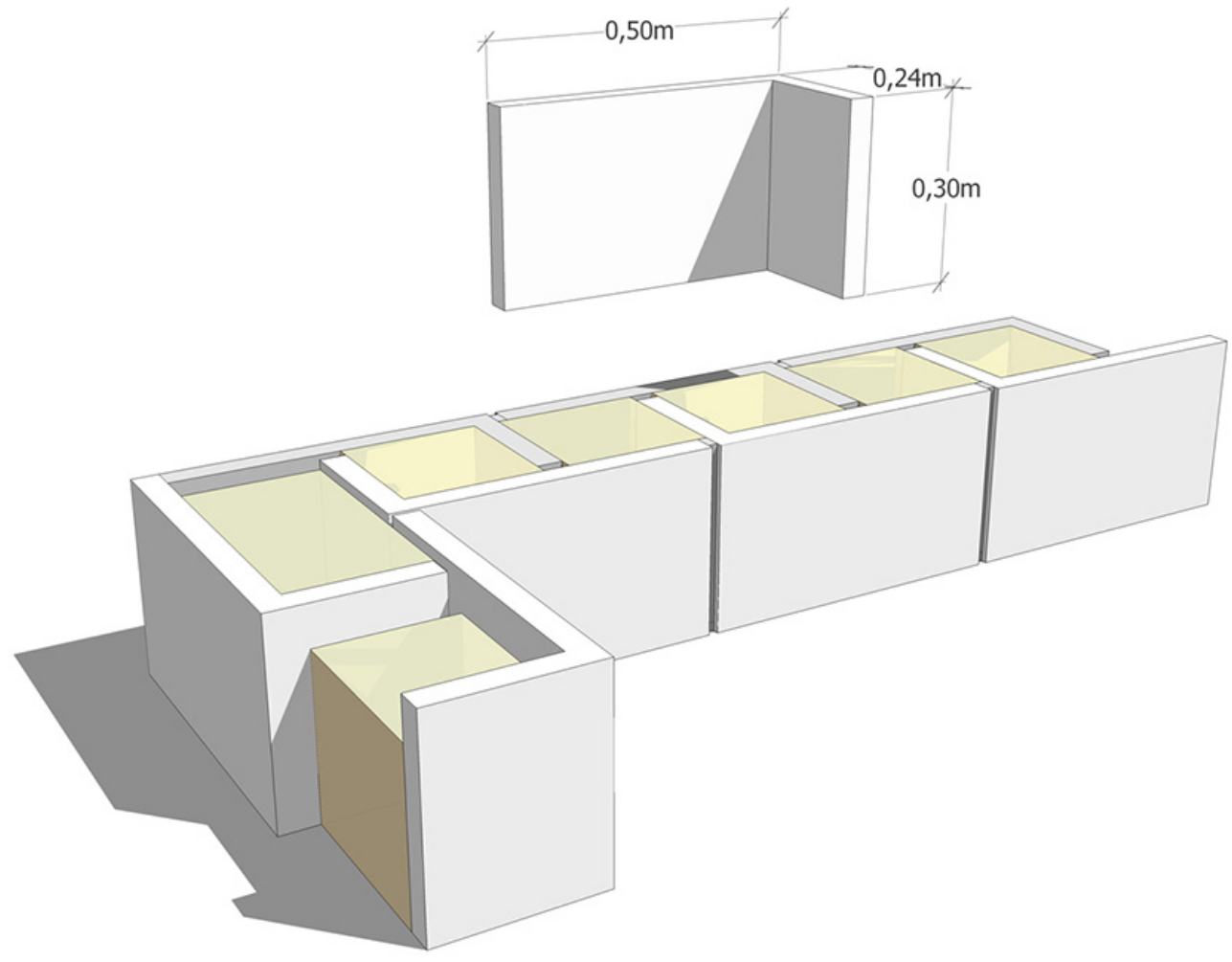

Figura 9. Infografía de las piezas prefabricadas utilizadas y su montaje. 


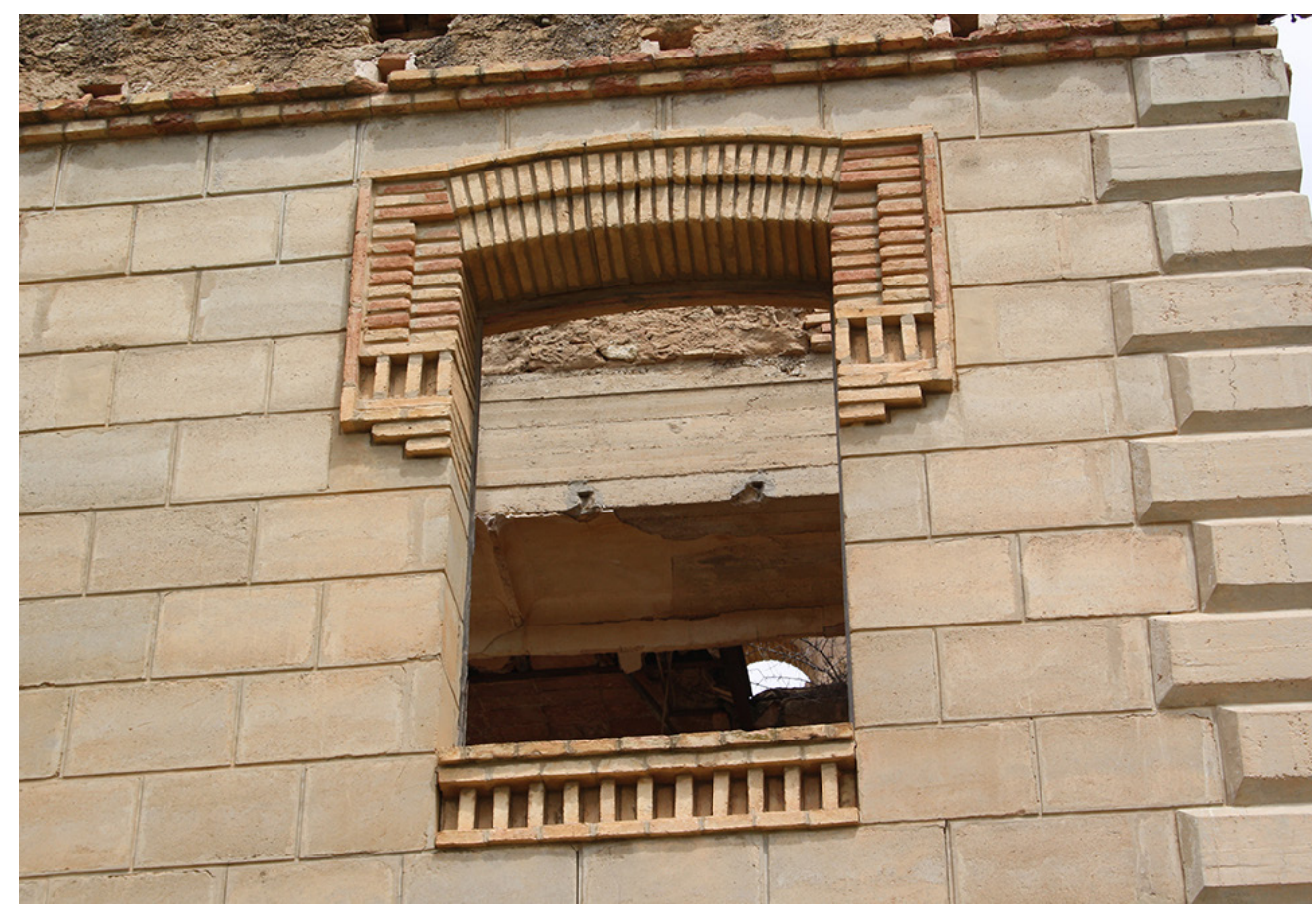

Figura 10. Resolución de dinteles y alfeizares de los vanos con ladrillo cerámico.

Otro aspecto que demuestra que el uso de un sistema de piezas prefabricadas aún se encontraba lejos de su plena inserción es que no existe una coordinación dimensional entre la longitud de las edificaciones y el módulo de las piezas empleadas. ${ }^{4}$ Como resultado, se hace necesario realizar ajustes mediante la rotura de piezas para acomodar las dimensiones, provocando una minoración en su agilidad constructiva.

Aunque no se tiene constancia ni documentación gráfica del proceso constructivo seguido para la formación de estos muros, según las técnicas coetáneas de la época, y siguiendo la premisa de simplificación y racionalización del proceso, la hipótesis planteada es que su ejecución podría haberse resuelto mediante el empleo de gatos metálicos y cuartones de madera. Para ello, dispuestas las piezas de toda una hilada asentadas con mortero de cemento, se dispondrían cuarterones de madera por el extradós para impedir que se abran las piezas en el momento del vertido del hormigón, mediante el uso de mordazas o gatos metálicos de encofrar, similares que los empleados hoy en día para los encofrados y que no distan mucho de los empleados en principio de siglo para el mismo fin. Posteriormente se procedería al vertido y compactación del hormigón mediante picado en toda la longitud de la hilada (Figura 11).

Sobre la utilización de piezas prefabricadas empleadas como encofrado perdido se tiene constancia de patentes y procedimientos a principios del siglo XX, aunque no será hasta la publicación de Petrignani en 1968, donde aparecerán repre- sentando exactamente este tipo de piezas definidas como modelo "Ambi” (19).

A pesar de que esta técnica no ha tenido continuidad en España, se han seguido utilizando piezas análogas a las estudiadas $^{5}$ en países como Estados Unidos o Australia. Por otro lado, podría decirse que el sistema de utilizar piezas a modo de encofrado perdido para configurar un cerramiento heterogéneo y a su vez portante, ha seguido desarrollándose en un proceso continuo de reducción de costes, tiempo y aumento de prestaciones, como es el caso de la utilización de unidades modulares de poliestireno expandido rellenos de hormigón, que permite dotar de aislamiento térmico a la sección del muro. ${ }^{6}$

\subsection{Caracterización y comportamiento estructural de los materiales}

Es representativo que, tras casi noventa años de estar construidas sin ningún tipo de mantenimiento o cuidados y en un entorno climatológicamente muy adverso (20), estas edificaciones presentan un inmejorable estado de conservación, lo que denota a priori la calidad y durabilidad del sistema empleado ${ }^{7}$.

El total desconocimiento de sistema constructivo y la inexistencia de referencias, justifica profundizar en su conocimiento para averiguar cuál fue el proceso de fabricación seguido en sus piezas prefabricadas, o qué características y propiedades mecánicas presentan, ante la posibilidad de que algunas

\footnotetext{
4 Tras el levantamiento de los diferentes edificios y teniendo en cuenta la longitud de la pieza prefabricada, no se ha encontrado ninguna relación dimensional entre ambos.

${ }_{5}$ Puede comprobarse la gran popularidad en la utilización de piezas prefabricadas de hormigón en Estados Unidos en la National Concrete Masonry Association.

${ }^{6}$ En la actualidad existen diversas casas comerciales que siguen utilizando productos análogos más desarrollados, como por ejemplo la empresa estadounidense Syntheon.

7 Según registros existentes de temperaturas en la provincia de Teruel, se han comprobado temperaturas mínimas de $-13.1^{\circ}$ o máximas $38,2^{\circ}$ en la población de Palomar.
} 


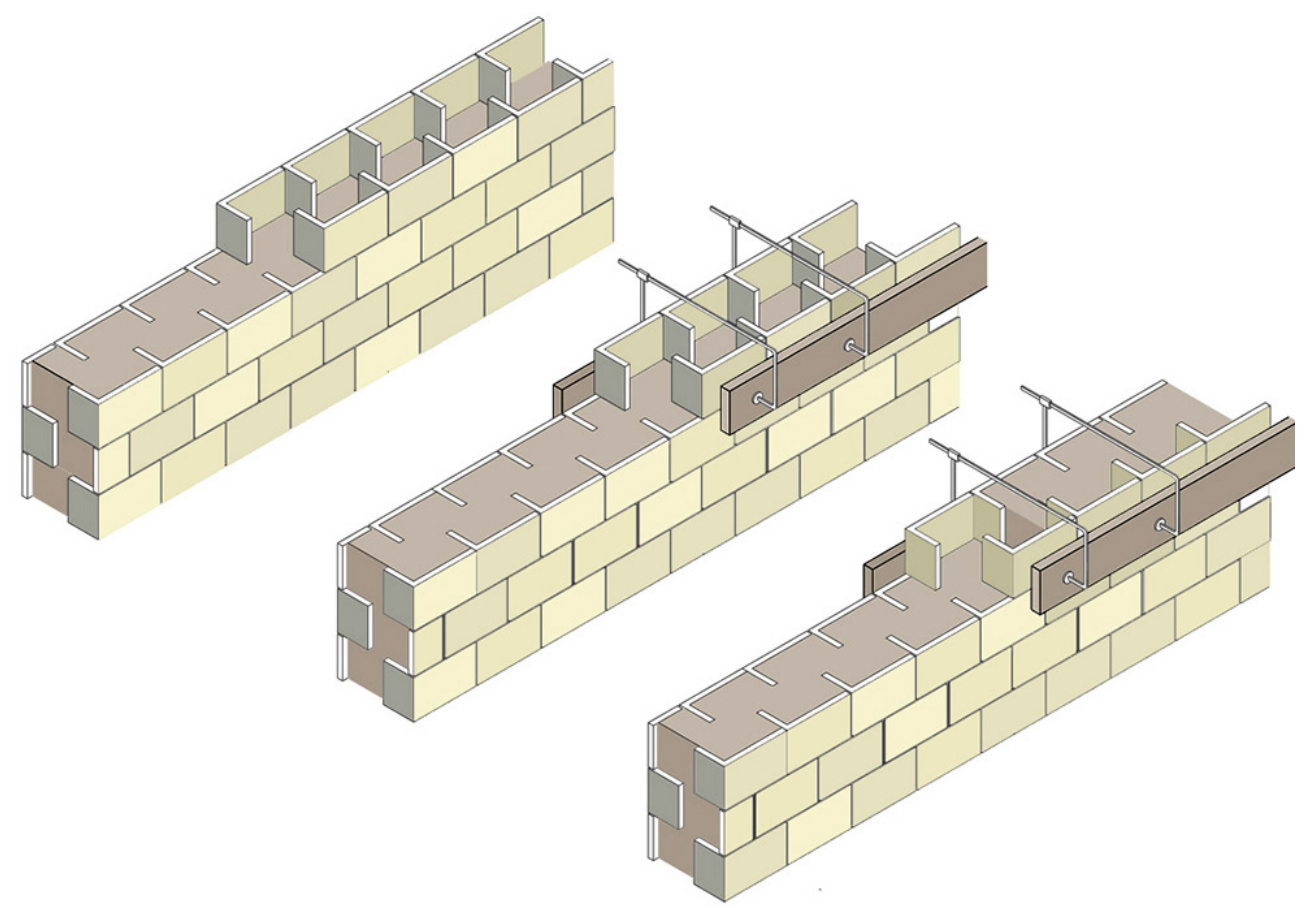

Figura 11. Infografía sobre la hipótesis de ejecución de los muros.

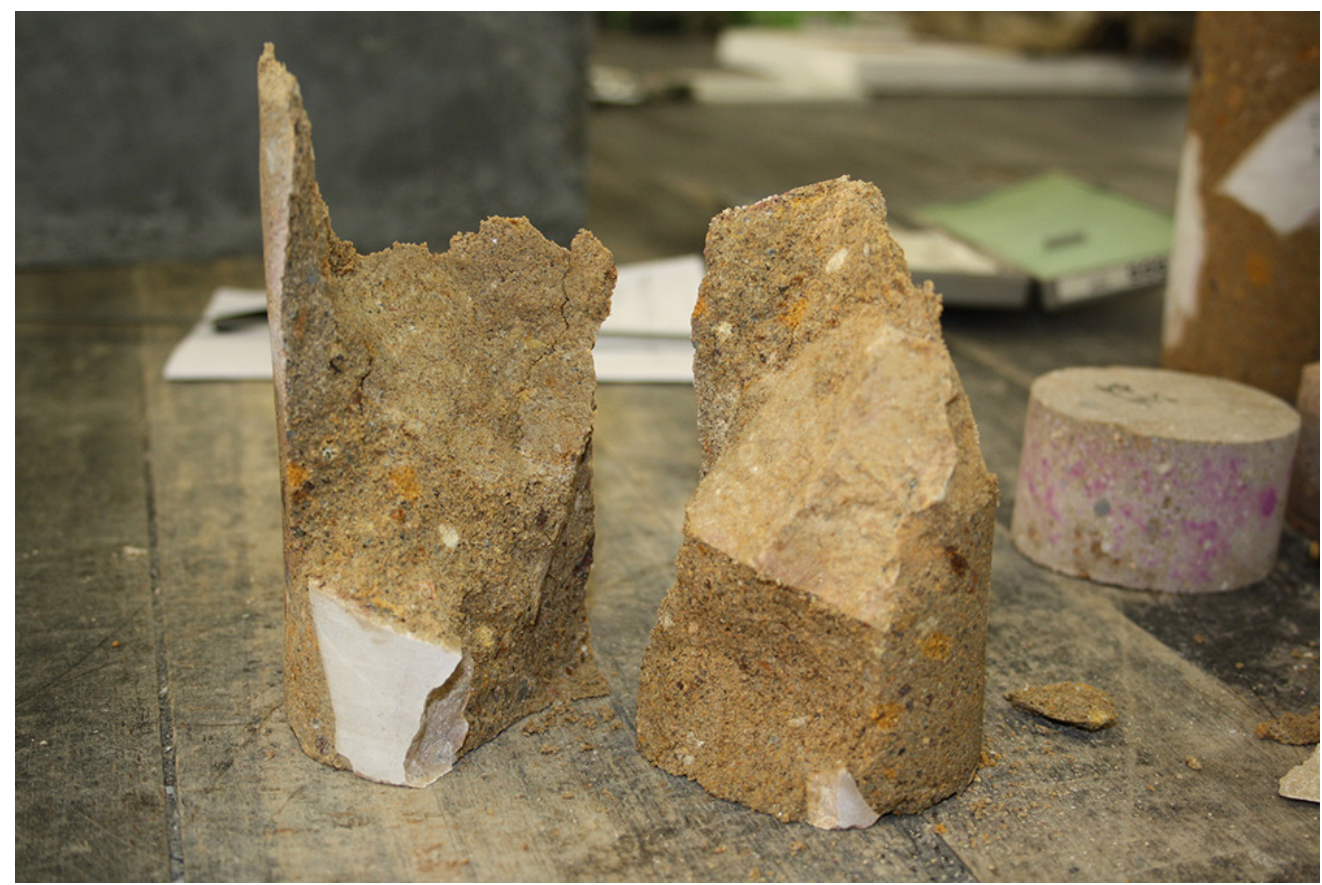

Figura 12. Resultados de los testigos tras los ensayos mecánicos.

de estas edificaciones pudieran verse sometidas a alguna intervención o rehabilitación en el futuro.

Para ello, se ha procedido a la realización de una batería de ensayos tras la extracción de testigos y su análisis en laboratorio (Figura 12), permitiendo determinar una mínima caracterización tanto de tensión, porosidad o densidad tanto de las distintas piezas de hormigón utilizadas como del relleno de los muros.

Según los resultados de los ensayos realizados (Tabla 1), puede observarse que la piedra artificial no presenta una compacidad muy alta, obteniéndose resistencias a compresión relativamente bajas respecto al resto de materiales empleados en la configuración del muro. Esta situación es suplida mediante el uso de grandes espesores que permite disipar las solicitaciones recibidas. A simple vista queda evidenciada una composición del mortero con distribución granulométrica muy dispar, incluso con inserción de áridos gruesos y material orgánico, alejada de la descrita en el Proyecto (21), por lo que puede afirmarse que la fabricación de estas piezas podría haberse realizado en las proximidades de la obra, o bien mediante un proceso industrial poco cuidado. 
Tabla 1. Caracterización materiales según los diferentes testigos ensayados.

\begin{tabular}{|l|c|c|c|}
\hline \multicolumn{1}{|c|}{ Material } & $\mathbf{N}^{\mathbf{0} \text { testigos }}$ & Tensión (MPa) & Densidad (Kg/m $\mathbf{m}^{\mathbf{3}}$ \\
\hline Piedra Artificial & 3 & 9,19 & 2,087 \\
\hline Pz. Prefabricada & 6 & 27,52 & 2,189 \\
\hline Hormigón interior & 2 & 21,63 & 1,909 \\
\hline
\end{tabular}

En cuanto a las piezas prefabricadas de hormigón en forma de " $L$ ", puede observarse que presentan valores de resistencias a compresión altas, bastante próximas a los valores de los hormigones actuales. Esta condición, junto al aspecto, granulometría y densidad de los testigos, puede afirmarse que previsiblemente estas piezas se hayan producido desde la industria, en un proceso con un adecuado control de dosificación, vibrado y curado, que han permitido obtener como resultado, piezas de elevada resistencia y durabilidad.

Respecto al hormigón empleado para el relleno interior de los muros, aunque presenta alta resistencia mecánica (tabla 1), muestra una granulometría poco cuidada ante la escasa correlación dimensional de los áridos empleados. Además, se ha podido constatar una elevada disparidad de resultados en los diferentes testigos ensayados, con la existencia de coqueras incluso de material vegetal, por lo que puede entenderse un proceso de ejecución muy descuidado ${ }^{8}$, reflejado en las continuas desavenencias entre la Administración y la constructora durante la ejecución de los trabajos (22).

Con todo ello, aunque existe un elevado contraste entre las resistencias mecánicas de los diferentes elementos que configuran los muros portantes, el espesor de los muros de más de $60 \mathrm{~cm}$, y el efecto de confinamiento que proporcionan las piezas prefabricadas, hacen que su resistencia mecánica esté muy por encima de las solicitaciones requeridas en estas edificaciones.

\section{CONCLUSIONES}

La conjunción de diversas circunstancias en la ejecución de estas construcciones ferroviarias, en una época económicamente adversa y la necesidad de hacer frente a un gran número de edificaciones en breve periodo de tiempo, potenció en gran medida la experimentación con nuevos materiales y sistemas constructivos que posibilitaran su ejecución.

El tratarse de edificaciones industriales ligadas al ferrocarril facilitó la transferencia de los últimos productos provenientes de la industria fruto de su desarrollo y de los avances técnicos, alejándose de ciertos complejos de la arquitectura academicista. En cambio, por tratarse de un proyecto gubernativo debieron acomodar su lenguaje industrial a un estilo más público y cercano como imagen de las políticas de Estado.

Obviamente, la inserción de estos nuevos productos debió convivir necesariamente con una construcción tradicional, donde los operarios aún faltos de destreza en el manejo de las últimas técnicas y sistemas constructivos, asimilarán su aplicación utilizándolas de forma equivalente a los métodos cotidianos. Aún así, será evidente el inicio de la ruptura con toda la cultura constructiva tradicional, estableciéndose como un punto de inflexión en la historia de la construcción actual, donde se procederá a revisar o reinterpretar las técnicas tradicionales ante la presencia de los nuevos materiales.

Aún con las limitaciones de la época, el uso de piezas prefabricadas arrojó innumerables ventajas en el proceso constructivo de estas edificaciones, pretendiendo continuar con el afán de reducción de costes y optimización de tiempos, implantando un sistema de ejecución más racional pero sin renunciar a la imagen pretendida al exterior.

Además, en cuanto a la caracterización de las piezas prefabricadas utilizadas en estas edificaciones ferroviarias, puede afirmarse que, incluso encontrándose en los inicios de la introducción de elementos prefabricados, sorprende la calidad de las piezas empleadas, comprobando, como mejor testigo de su comportamiento, su buen estado de conservación tras casi noventa años de su ejecución.

Sin embargo, sorprende la falta de continuidad en el tiempo a pesar de la flexibilidad y calidad de este tipo de piezas. No se tiene constancia real si la dificultad y coste del transporte de estas piezas hasta la ubicación de las obras, la falta de pericia de los operarios, o la deficiente ejecución en el relleno del alma de los muros, hicieron finalmente desestimar la continuidad de este sistema y modelo de piezas prefabricadas.

Por todo ello, la existencia de todas estas edificaciones como único ejemplo de este singular sistema constructivo, las configura como un crisol de experimentación de los nuevos materiales y toda la tecnología desarrollada en la época de su construcción, con la intención clara de optimizar al máximo en los tres frentes principales de toda actuación: los materiales, la mano de obra y el tiempo de ejecución.

\section{REFERENCIAS}

(1) Aguilar, I. (1998). Arquitectura Industrial. Concepto, método y fuentes. Valencia: Museu d’Etnología de la Diputación de Valencia.

(2) Comerma, J. (1886). Aplicación de los materiales hidráulicos. Revista Obras Públicas. IV (24): 195-196

\footnotetext{
${ }^{8}$ Existen diversos informes redactados por el ingeniero Gabriel Roca a $6^{\circ}$ Jefatura de Ferrocarriles y Construcciones, denunciando la detección de diversos problemas, como en la ejecución de los trabajos en los rellenos de sus muros de la estación de Pitarra, destacando lo pobre del mortero empleado.
} 
(3) Atlas Nacional de España. Sección VII Transporte por ferrocarril.(2008). Instituto Geográfico Nacional. pp 23.2-3 http://www.ign.es/ane/ane1986-2008/

(4) Comín, F., Martín, P., Muñoz, M., Vidal, J. (1998). 150 años de historia de los ferrocarriles españoles: La era de las concesiones a las compañías privadas. Madrid: Fundación de los Ferrocarriles Españoles. Gráficas Muriel.

(5) Rahola, S. (1916). Tratado de Ferrocarriles. Tomo IV, Estaciones y movimientos. p.40, Madrid: Sucesores de Rivadeneyra.

(6) Aguilar, I. (1988). La estación de ferrocarril: Puerta de la ciudad. Valencia: Generalitat Valenciana, Conselleria de Cultura, Educación y Ciencia.

(7) Alcala, N. (1932). Plan preferente de ferrocarriles de urgente construcción. Gaceta de Madrid. 105: 337-339

(8) Prieto, L., Enguiz, J. (1996). El transpirenaico del Noguera Pallaresa y el ferrocarril Lleida-Teruel-Baeza. Barcelona: Ferrocarrils de la Generalitat de Catalunya.

(9) Machimbarrena, V. (1930) La mejora y ampliación de la red ferroviaria española. Revista de Obras Públicas 74(2546):137-138

(10) VV.AA. (1986). El desarrollo económico de España. Informe de 1962. Colección: Biblioteca de Economía Española. No: 16. Barcelona: Orbis.

(11) Anuncio del concurso de la línea de ferrocarril de Teruel a Alcañiz. (1926). Gaceta de Madrid. IV(356):1618

(12) Estevan B. Proyecto de Replanteo del ferrocarril de Teruel a Alcañiz. Archivo General de la Administración. Obras Públicas, Caja: 25/03258. Madrid.

(13) Verdejo, P. (2014). La estaciones intermedias de ferrocarril. La sección "non nata" Teruel-Alcañiz. (Tesis doctoral no publicada). Valencia: Universidad Politécnica de Valencia.

(14) Valdés, N. (1870). Manual del Ingeniero y Arquitecto. $2^{\circ}$ Ed. p 632. Madrid.

(15) García, A. M. (1997). La evolución de las cimentaciones en la historia de la arquitectura, desde la prehistoria hasta la primera Revolución Industrial. Madrid. Universidad Politécnica de Madrid.

(16) Nacente, F. (1890). El constructor moderno, Tratado Teórico y Práctico de Arquitectura y Albañilería. p 101-118. Barcelona: Ignacio Monrós y Compañía.

(17) Fabricación de piedra artificial. (1874) Revista Obras Públicas. 22(5): 59-60

(18) Portuondo, B. (1877). Lecciones de Arquitectura. Primera Parte. Madrid: Memorial de Ingenieros.

(19) Petrignani, A. (1968) Tecnologías de la arquitectura. Barcelona. Ed. Gustavo Gili.

(20) Gobierno de Aragón. Clima / Datos climatológicos. 08/10/2014, de Instituto Aragonés de Estadística. http://www.aragon.es/iaest

(21) Estevan B. Pliego de Condiciones Técnicas del Proyecto de Replanteo del ferrocarril de Teruel a Alcañiz. Archivo General de la Administración. Obras Públicas, Caja: 24/12274. Madrid.

(22) Roca G. Informe de la $6^{\circ}$ Jefatura de Ferrocarriles y Construcciones sobre deficiencias observadas en el edificio de viajeros de la estación de Pitarra. Archivo General de la Administración. Obras Públicas Caja: 26/22063. Madrid. 